\title{
An online module series to prepare pharmacists to facilitate student engagement in patient-centered care delivery: development and evaluation
}

This article was published in the following Dove Press journal:

Advances in Medical Education and Practice

16 June 2012

Number of times this article has been viewed

\section{Rosemin Kassam ${ }^{\prime}$ \\ Mona Kwong' \\ John B Collins ${ }^{2}$}

'Faculty of Pharmaceutical Sciences, ${ }^{2}$ Department of Educational Studies, University of British Columbia,

Vancouver, Canada
Correspondence: Rosemin Kassam Faculty of Medicine: School of Population and Public Health, University of British Columbia, \#265-2206 East Mall, Vancouver, British Columbia, Canada V6T IZ3

Phone + | $6048227|8|$

Email rosemin.kassam@ubc.ca
Introduction: Accreditation bodies across North America have adopted revised standards that place increased emphasis on experiential education and preceptors to promote and demonstrate patient-centered, pharmaceutical care practices to students. Since such practices are still evolving, challenges exist in recruiting skilled preceptors who are prepared to provide such opportunities. An online educational module series titled "A Guide to Pharmaceutical Care" (The Guide) was developed and evaluated to facilitate this transition. The objectives of this paper are: (1) to describe the development of the modules; and (2) to present the evaluation results from its pilot testing.

Methods: The Guide was developed as an online, self-directed training program. It begins by providing an overview of patient care (PC) philosophy and practice, and then discusses the tools that facilitate PC. It also provides a range of tips to support students as they provide PC during their experiential learning. Pharmacists participating in the pilot study were recruited using purposive and snowball sampling techniques. A pre-post quantitative survey with additional open-ended questions was used to evaluate the modules.

Results: The modules incorporated a variety of teaching strategies: self-reflection exercises, quizzes to review important concepts, quick tips, flash cards, and video clips to illustrate more in-depth learning. Thirty-two pharmacists completed the pre-post assessment and reported significant increases in their confidence because of this training. The most influenced outcome was "Application of techniques to facilitate learning opportunities that enable pharmacy students to practice pharmaceutical care competencies." They also indicated that the training clarified necessary changes in their teaching techniques as well as increased their own practice skills.

Conclusion: The study results indicated that a series of self-paced online modules with appropriate content improved the pharmacists' confidence to nurture students' experiential learning for PC practice as well as enhanced their PC knowledge and skills within their own practices. Keywords: preceptor, clinical instructor, experiential, education, pharmaceutical care

\section{Introduction}

Colleges and schools of pharmacy throughout the US and Canada are redeveloping their curricula to meet the pharmacy profession's evolving mandate to provide "patient care that ensures optimal medication therapy outcomes." Association has defined patient care (PC) as an "outcomes-oriented pharmacy practice that requires the pharmacist to work in concert with the patient and their patient's other healthcare providers to promote health, to prevent disease, and to assess, monitor, initiate, and modify medication use to assure that drug therapy regimens are safe and effective."2 The Accreditation Council for Pharmacy Education (ACPE) and the Canadian Council for Accreditation of Pharmacy Programs (CCAPP) have both adopted revised standards 
and guidelines to reflect this vision. ${ }^{3,4}$ These standards provide considerable delineation for the experiential education of pharmacy students, including direction on the development and conduct of such experiences. The most notable change to the standards is the specification that experiential education must foster independent thinking, promote self-confidence, teach collaboration within a multidisciplinary team, and encourage the practical application of patient centered care - including the knowledge, skills, and attitudes to provide patient-centered and population-based care. ${ }^{3-6}$ Experiential education is defined as a methodology in which educators engage learners in direct experiences and targeted reflection to increase knowledge and develop skills, behaviours, and values. ${ }^{7}$

With future graduates modeling themselves and their practices on examples encountered during their academic training, experiential learning serves a critical role in the students' development. ${ }^{6}$ It is reasonable therefore for accreditation standards to place increased emphasis on experiential learning, while concurrently promoting the role of pharmacists as preceptors. In pharmacy, a preceptor is a pharmacist who interacts, directs, and supervises students during their experiential learning under the guidance of the partner school, and takes responsibility for promoting and monitoring the students' competence and skills development. ${ }^{7}$ In addition to teaching knowledge and skills, preceptors are expected to demonstrate how to practice patient centered care and to promote field environments that enable students to be active participants in direct PC activities. Dugan explicitly clarifies:

\footnotetext{
By modeling for students what patient centered care looks like and feels like, and logistically, how it can be integrated in day-to-day practice, pharmacists can pave the road that students not only will want to follow, but will be able to travel. Without such role models, patient centered care is just words without focus or real-world meaning to students. Colleges and schools of pharmacy are dependent upon preceptors for this practical, hands-on experience. ${ }^{6}$
}

Accordingly, pharmacy preceptors are being asked to adapt their practices and educational strategies to ensure that students achieve the intended educational goals and objectives. ${ }^{8}$ Unfortunately, several barriers including lack of confidence among pharmacists, lack of best-practice models, and a product-based reimbursement model are limiting the widespread implementation of patient centered care practices. ${ }^{9-13}$ Additionally, the profession's pursuit of a patient oriented practice over the past five decades has resulted in the introduction of several practice models including: (1) the drug information practice model; (2) the clinical pharmacy practice model; (3) the pharmaceutical care practice model; and (4) the Medication Therapy Management model. ${ }^{14,15}$ These competing models have resulted in confusion, debate, and divisiveness within the profession because more attention has been paid to their differing terminologies, rather than their common patient centered care purposes, processes, and end result professional activities. ${ }^{14,15}$ In the context of shifting academic standards for experiential learning, schools must offer educational programs that enhance preceptorship skills as well as clarify PC concepts.

Several schools employ a variety of preceptor-training approaches such as face-to-face educational seminars and workshops, handbooks outlining teaching and evaluation procedures, one-on-one discussions of experiential teaching methodology, and articles or books on experiential education and supervision. The challenges of these traditional methods are three-fold: time, cost, and accessibility. ${ }^{16,17}$ With almost universal access to the internet, anecdotal discussions with the University of British Columbia preceptors have pointed to the Internet as an ideal delivery platform for effective and accessible educational content.

In 2007, a group of pharmacy faculty at the University of British Columbia leading the implementation of pharmaceutical care initiatives at pharmacy sites began to develop an online educational module series titled "A Guide to Pharmaceutical Care" (The Guide) for preceptors and pharmacists interested in becoming preceptors. This Guide can be accessed through the URL http://www.preceptoreducation.ca by creating a personal username and password or as a guest by clicking on the "login as a guest" button. The Guide begins with an overview of Hepler and Strand's model of patient centered care philosophy and practice, and then discusses tools that facilitate providing PC. It also provides a range of tips to support students as they provide $\mathrm{PC}$ during their experiential learning. The objectives of this paper are: (1) to describe how The Guide's modules were conceived and developed; and (2) to present the results from its implementation and pilot testing.

\section{Methods}

This two-part project spanned four years from 2007 to 2010. It began by developing an online version of The Guide, followed by a pre-post study to evaluate preceptor confidence to facilitate students' on-site patient centered learning following the completion of The Guide. The planning and development of the project required three years and included faculty from the University of British Columbia and a software development expert. The University of British Columbia's Behavioral and Research Ethics Board approved the ethics of the project. 


\section{Developing the online modules}

The module packages were designed for an on-line, selfdirected training program for pharmacists wishing to acquire preceptor skills. The design of the modules was guided by the following criteria: (1) it must be relevant to pharmacists and pharmacy preceptors; (2) it must be supported by the health and pharmacy education literature; (3) it must encourage active rather than passive learning by engaging learners though activities and videos; (4) it must be accessible at any time and in any sequence; and (5) it must be succinct and short, taking no more than 30 minutes to complete. To determine the learning topics for the module package, the evaluations of the Advanced Pharmacy Practice Education (APPE) programs, focus group discussion, annual written feedback, and anecdotal discussions with preceptors were consulted. ${ }^{12,18,20,21}$ A live version of the program was initially developed and delivered (2000-2008) to validate the relevance and appropriateness of the topics, and which later formed the basis of The Guide. The content was grouped into 11 major themes including: (1) getting started as a clinical instructor; (2) pharmaceutical care philosophy; (3) benefits of pharmaceutical care; (4) pharmaceutical care practice model; (5) pharmaceutical care process; (6) therapeutic relationship; (7) patient interview; (8) drug-related problems (DRPs); (9) thought process to identify DRPs; (10) professional writing; and (11) pharmacy care plan.

The online modules were created using Moodle (Modular Object Oriented Dynamic Learning Environment) Trust's open-source learning management system software (Moodle HQ, Perth, Australia). In addition to free access, Moodle enables the creation of course content using various platform interface tools such as standard HTML, Adobe Flash (Adobe Systems Incorporated, San Jose, CA), JavaScript database (Oracle Corporation, Redwood Shores, CA), MySQL database (Oracle Corporation), and Apache Web Server (The Apache Software Foundation, Forest Hill, MD), thereby facilitating learner-centered environments in which learners can strengthen their understanding of concepts and processes independently, engage in self-reflection, and partake in interactive hands-on activities. ${ }^{19}$ The design of the modules was guided by the following five principles: (1) easy and fluid navigation; (2) no item more than three clicks away; (3) all navigation items explicitly defined; (4) clear and comprehensive directions for using the site, including navigation, flash objects, and videos; and (5) all modules kept short with small images to minimize loading time for low bandwidth users. The program's graphics were purchased through royalty-free websites and modified as required. The URL and server space were purchased to house the course at http://www.preceptoreducation.ca. The users could access the modules in either of two ways: by creating their own personal login account, or through guest access.

Once developed, the content was peer-reviewed for usability and beta-tested by five university faculty members across Canada as well as three pharmacy practitioners from community and institutional sites. The participants provided feedback regarding the ease-of-use of the modules, the look and feel of the overall program, and the existence of any significant gaps or errors in the modules' content. Navigation problems, typographical, and grammatical errors were corrected prior to pilot testing. The module package received a final review and approval from the University of British Columbia's Continuing Pharmacy Professional Development Office, which is responsible for assigning continuing education units.

\section{Pilot testing Participants}

Pilot testing was limited to all pharmacists serving as preceptors with the university's APPE programs who had not previously participated in the program's live version. The majority of the participants included institutional preceptors, as all community APPE preceptors had previously participated in the live version. Therefore, only those community pharmacists who expressed interest in becoming future preceptors were recruited for the pilot study.

The recruitment process used purposive and snowball sampling techniques, and was facilitated by managers and coordinators from community and institutional pharmacy settings affiliated with the University's APPE programs. Site mentors were best able to champion the program by aligning it with their respective organizations' visions and expectations. The mentors were briefed about the module series through face-to-face, telephone, and video conferencing meetings, and were then asked to send one representative - someone who could spearhead promoting the module package at their site - to attend a full day orientation. At the orientation, a trained facilitator guided the attendees as they viewed the selected modules and, in small groups, planned how to promote module delivery at their respective organizations given their differing logistics. The participants received an honorarium to cover travel and incidental costs. The institutional sites committed time during work hours for their pharmacists to complete the package's various modules, while community pharmacists completed them in their own time.

\section{Data collection}

The study design used a simple pre-self-assessment $\rightarrow$ intervention $\rightarrow$ post-self-assessment format that was delivered 
online. The pre-assessment was completed prior to beginning the modules. The intervention was the 11-module online series, which the pilot study participants completed over an eightmonth period. After completing the final module, they filled out the post-assessment survey and completed a brief fourquestion program evaluation. The pre-post self-assessment used a four-point scale ( 1 = none, 2 = slight, 3 = moderate, $4=$ high) to report their confidence levels in facilitating student learning across nine performance outcomes. The program evaluation component (post-only) used a five-point scale ( 1 = strongly disagree, $2=$ disagree, $3=$ neutral, $4=$ agree, $5=$ strongly agree) for participants to report whether the material was presented in an understandable manner, whether the material was organized, whether the modules met the stated learning objectives, and whether the exercises were helpful and effective. Finally, using open-ended responses, the pharmacists reported their reasons for participating in the training, the key learning that occurred, and what changes they intended to make as preceptors after completing the training. The participants also submitted a portfolio with artifacts of their own learning, which included personal reflections and embedded assignments that qualified for continuing education credits.

\section{Analysis}

Pharmacists who completed all 11 modules within the allocated time were included in the final analysis. The questionnaire responses were downloaded onto a spreadsheet (Microsoft Excel 2000) and then collated and evaluated using SPSS 15.0 for Windows (SPSS Inc, Chicago, IL). Descriptive statistics were calculated using frequencies, means, and standard deviations. Pre-post comparisons were conducted using paired $t$-tests with the significance level set a priori at $P<0.05$. Finally, the qualitative responses to open-ended questions were grouped under common themes and then analyzed.

\section{Results}

\section{Module development results}

Table 1 summarizes the objectives of the 11 modules developed for The Guide. The design of each module followed a consistent format beginning with "Objectives" and concluding with the "Role of the practice educator."

Figures 1 and 2 depict the first and last screen of the "Pharmaceutical Care Practice Model" module. The modules incorporated a variety of teaching strategies to engage users and highlight important concepts such as self-reflection exercises, quizzes to review important concepts, quick tips, and flash cards as reminders to review important information. To allow for individualized learning, the modules provided a short synopsis
Table I "A Guide to Pharmaceutical Care": overview of modules

\begin{tabular}{|c|c|}
\hline Module topic & Module goals \\
\hline $\begin{array}{l}\text { Getting started } \\
\text { as a clinical } \\
\text { instructor }\end{array}$ & $\begin{array}{l}\text { To have a common understanding of terminology } \\
\text { and practice-educator responsibilities to prepare } \\
\text { for student arrival }\end{array}$ \\
\hline $\begin{array}{l}\text { Pharmaceutical } \\
\text { care philosophy }\end{array}$ & $\begin{array}{l}\text { To help practice educators understand the } \\
\text { pharmaceutical care philosophy of practice }\end{array}$ \\
\hline $\begin{array}{l}\text { Benefits } \\
\text { of pharmaceutical } \\
\text { care }\end{array}$ & $\begin{array}{l}\text { To help practice educators understand why } \\
\text { pharmacy schools are emphasizing pharmaceutical } \\
\text { care competencies within their curricula }\end{array}$ \\
\hline $\begin{array}{l}\text { Pharmaceutical } \\
\text { care practice } \\
\text { model }\end{array}$ & $\begin{array}{l}\text { To present a proposed model of practice } \\
\text { that triages patients to receive different } \\
\text { levels of pharmaceutical care and to present } \\
\text { tools, processes, and vocabulary to facilitate } \\
\text { pharmaceutical care }\end{array}$ \\
\hline $\begin{array}{l}\text { Pharmaceutical } \\
\text { care process }\end{array}$ & $\begin{array}{l}\text { To provide an overview of the pharmaceutical } \\
\text { care process }\end{array}$ \\
\hline $\begin{array}{l}\text { Therapeutic } \\
\text { relationship }\end{array}$ & $\begin{array}{l}\text { To provide an overview of the therapeutic } \\
\text { relationship concept to better understand } \\
\text { the skills and processes that lead to patient } \\
\text { involvement in decisions about their drug therapy }\end{array}$ \\
\hline Patient interview & $\begin{array}{l}\text { To present a systematic approach for } \\
\text { interviewing patients (for basic pharmaceutical } \\
\text { care, disease management, and comprehensive } \\
\text { pharmaceutical care) }\end{array}$ \\
\hline DRPs & $\begin{array}{l}\text { To understand what constitutes a drug-related } \\
\text { problem }\end{array}$ \\
\hline $\begin{array}{l}\text { Thought process } \\
\text { to identify DRPs }\end{array}$ & $\begin{array}{l}\text { To provide an overview of the "thought process" } \\
\text { to facilitate students' learning, decision making, } \\
\text { and self-reflection }\end{array}$ \\
\hline $\begin{array}{l}\text { Professional } \\
\text { writing }\end{array}$ & $\begin{array}{l}\text { To help practice educators understand principles } \\
\text { of documentation }\end{array}$ \\
\hline $\begin{array}{l}\text { Pharmacy } \\
\text { care plan }\end{array}$ & $\begin{array}{l}\text { To help practice educators understand what } \\
\text { constitutes a pharmacy care plan and its benefits }\end{array}$ \\
\hline
\end{tabular}

Adapted from "A Guide to Pharmaceutical Care." This Guide can be accessed through the URL: http://www.preceptoreducation.ca

Abbreviation: DRPs, drug-related problems.

on a given learning topic, links for more in-depth learning, and video clips to illustrate and contrast between different types of patient interviews. Figures 3 and 4 provide examples of some of the activities included within the modules.

\section{Pilot study results}

Thirty-two pharmacists submitted their learning portfolios for analysis, 29 were from five of the six institutional health regions and three were from community pharmacy settings. All the community pharmacists and one institutional pharmacist resided in Vancouver city where the school of pharmacy is located, while the remaining 28 came from outlying areas. No additional demographic information was collected. One institutional health region was unable to participate due to internal restructuring of administrative staff. The majority of the institutional pharmacists used their workplace computers 


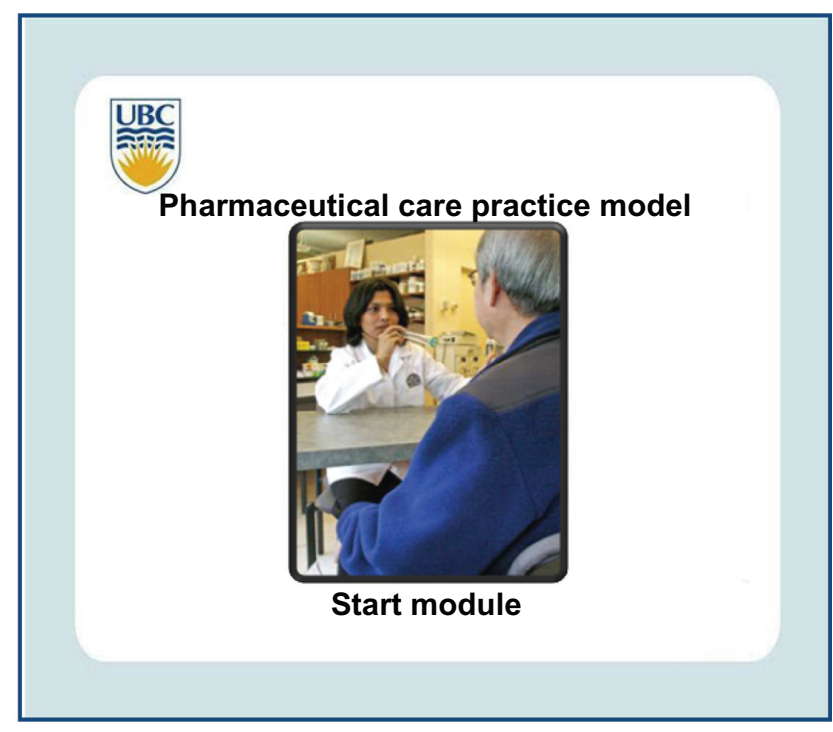

Figure I "Pharmaceutical Care Practice Model" opening screen shot. Reproduced from "A Guide to Pharmaceutical Care."

to complete the modules and their learning was supported though regular on-site meetings where they shared and discussed their experiences. Those who met in groups to review the modules reported that the discussions were beneficial because the conversations allowed for the sharing of ideas, learning from peers, and brainstorming how the module content could be applied to future precepting situations. In contrast, all the community pharmacists completed the modules at home and in their own time.

Because of this training, the pharmacists reported that their confidence was significantly increased for all nine learning outcomes (Table 2). For example, "Identification of appropriate patients to interview for disease management

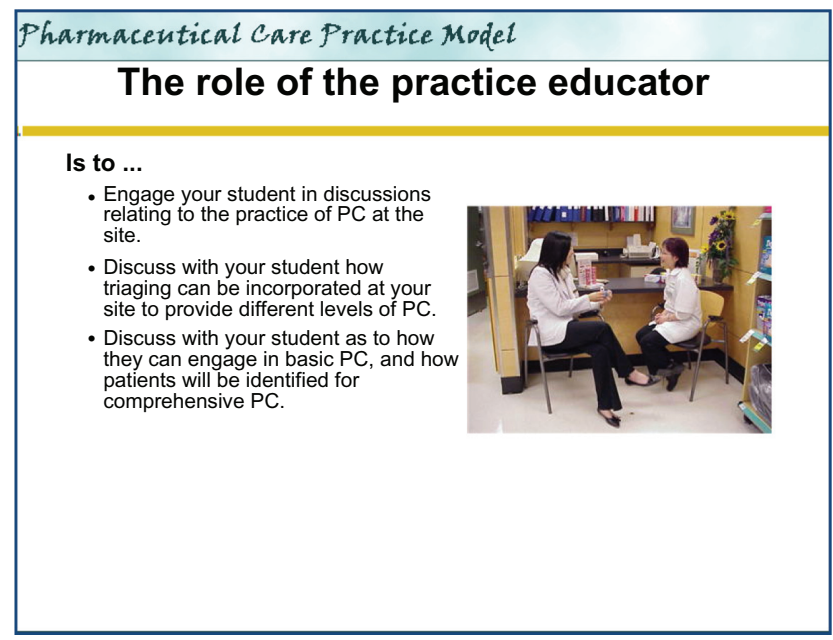

Figure 2 "Pharmaceutical Care Practice Model" closing screen shot. Reproduced from "A Guide to Pharmaceutical Care."

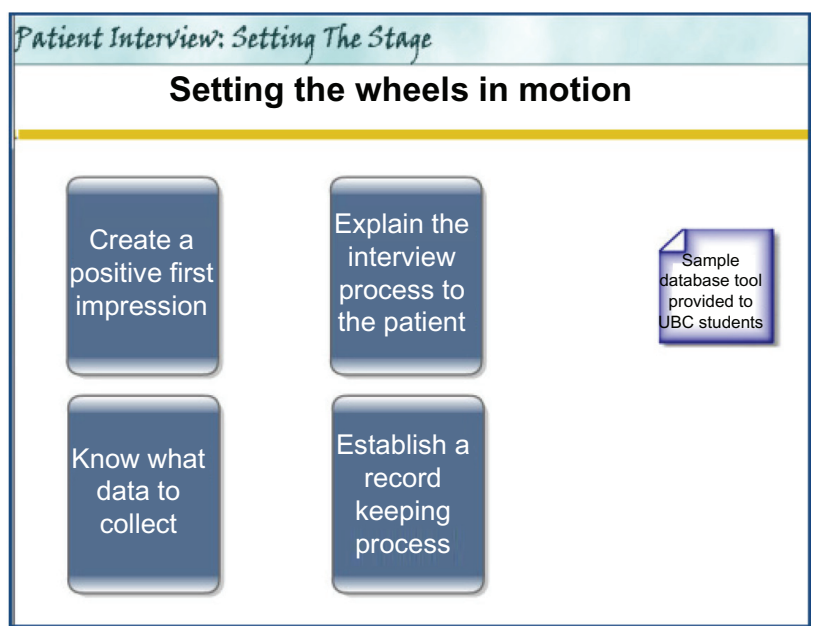

Figure 3 "Patient interview - setting the wheels in motion." Reproduced from "A Guide to Pharmaceutical Care."

and comprehensive pharmaceutical care," which received the highest pre-training confidence rating of $3.16 \pm 0.63$, increased further to $3.72 \pm 0.46$ after completion of the training (a 0.56 point or $17.7 \%$ increase, $P<0.001$ ). Similarly, confidence in "Evaluation of the student's decision making and clinical reasoning in initial/follow-up pharmacy care plan(s)" received the lowest pre-training rating of $2.59 \pm 0.71$, but increased to $3.41 \pm 0.50$ post-training (a 0.81 point or $31.3 \%$ increase, $P<0.001$ ). The learning outcome most influenced by the training was "Application of techniques to facilitate learning opportunities that enable pharmacy students to practice pharmaceutical care competencies," which received a 0.97 points or $36.1 \%$ increase $(P<0.001)$. The average pre-to-post gain for all nine competencies was 0.80 , an increase of $29.1 \%$.

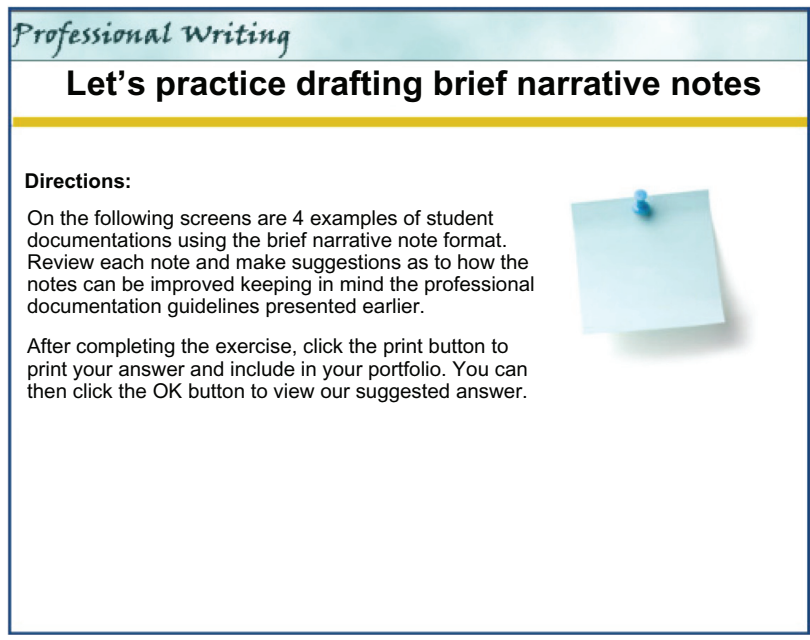

Figure 4 "Professional writing - let's practice drafting brief narrative notes." Reproduced from "A Guide to Pharmaceutical Care." 
Table 2 Preceptors' pre-post self-assessment of confidence gains to facilitate student engagement with pharmaceutical care processes $(\mathrm{n}=32)$

\begin{tabular}{|c|c|c|c|c|c|c|}
\hline \multirow{2}{*}{$\begin{array}{l}\text { Assessment questions (worded as } \\
\text { statements) }\end{array}$} & \multirow{2}{*}{$\frac{\text { Pre-confidence }}{\text { Mean (SD) }}$} & \multirow{2}{*}{$\frac{\text { Post-confidence }}{\text { Mean (SD) }}$} & \multirow{2}{*}{$\frac{\text { Pre-post }}{M_{\text {Pre }}-M_{\text {Post }}}$} & \multirow[t]{2}{*}{$P$-value } & \multirow{2}{*}{$\frac{\text { Normalized gain }}{{\mathrm{M} / \mathrm{sd}_{(\mathrm{pre})}}}$} & \multirow{2}{*}{$\frac{\text { Gain }}{\%}$} \\
\hline & & & & & & \\
\hline $\begin{array}{l}\text { I. Facilitate learning opportunities that enable } \\
\text { pharmacy students to practice pharmaceutical } \\
\text { care competencies }\end{array}$ & $2.69(0.64)$ & $3.66(0.48)$ & 0.97 & $<0.001$ & 1.52 & 36.1 \\
\hline $\begin{array}{l}\text { 2. Incorporate different levels of pharmaceutical } \\
\text { care at your site }\end{array}$ & $2.72(0.63)$ & $3.44(0.56)$ & 0.72 & $<0.001$ & 1.14 & 26.4 \\
\hline $\begin{array}{l}\text { 3. Provide constructive feedback to the student } \\
\text { on how to enhance therapeutic relationships }\end{array}$ & $2.66(0.75)$ & $3.53(0.5 \mathrm{I})$ & 0.875 & $<0.001$ & 1.16 & 33.0 \\
\hline $\begin{array}{l}\text { 4. Identify appropriate patients to interview } \\
\text { for disease management and comprehensive } \\
\text { pharmaceutical care }\end{array}$ & $3.16(0.63)$ & $3.72(0.46)$ & 0.56 & $<0.001$ & 0.88 & 17.7 \\
\hline $\begin{array}{l}\text { 5. Provide constructive feedback to the student } \\
\text { on patient interviewing skills for different levels } \\
\text { of pharmaceutical care provided }\end{array}$ & $2.88(0.55)$ & $3.69(0.47)$ & 0.813 & $<0.001$ & 1.14 & 28.2 \\
\hline $\begin{array}{l}\text { 6. Provide constructive feedback to the student } \\
\text { on how to formulate a drug related } \\
\text { problem statement }\end{array}$ & $2.84(0.63)$ & $3.69(0.47)$ & 0.844 & $<0.001$ & 1.34 & 29.7 \\
\hline $\begin{array}{l}\text { 7. Assist the student in assessing and developing } \\
\text { a logical and systematic approach to decision } \\
\text { making for individualizing drug therapy }\end{array}$ & $2.66(0.79)$ & $3.44(0.62)$ & 0.78 & $<0.001$ & 0.99 & 29.3 \\
\hline $\begin{array}{l}\text { 8. Facilitate the student's understanding and use } \\
\text { of different documentation tools available for } \\
\text { assessment and follow-up in the provision of PC }\end{array}$ & $2.66(0.79)$ & $3.47(0.5 \mathrm{I})$ & 0.81 & $<0.001$ & 1.03 & 30.4 \\
\hline $\begin{array}{l}\text { 9. Evaluate the student's decision making and clinical } \\
\text { reasoning in initial/follow-up pharmacy care plan(s) }\end{array}$ & $2.59(0.7 \mathrm{I})$ & $3.4 I(0.50)$ & 0.81 & $<0.001$ & 1.14 & 31.3 \\
\hline Total for all nine assessment issues & $2.76(0.50)$ & $3.56(0.33)$ & 0.80 & $<0.001$ & 1.19 & 29.1 \\
\hline
\end{tabular}

Abbreviation: PC, patient care.

The pharmacists explained their reasons for engaging with the modules in their open-ended reports. Table 3 summarizes these reasons and groups them into three categories: (1) enhancing preceptorship skills (23 pharmacists); (2) development of professional and personal skills $(\mathrm{n}=5)$; and (3) it was required by their employer $(n=7)$. Three pharmacists cited preceptorship skills and PC skills as their reasons. The pharmacists' open-ended responses also corroborated their numerical responses, which cited greater confidence to set learning experiences for students, providing effective feedback and evaluation, and fostering PC related skills (Table 4). Furthermore, the training helped them clarify necessary changes in their teaching methods (Table 5) such as better planning of experiential experiences, ensuring the students are exposed to a variety of $\mathrm{PC}$ opportunities, and providing more effective student support, feedback, and evaluation. They also reported increases in their own practice skills specifically in their use of PC tools and documenting their practices.

The pharmacists' evaluations of The Guide were similarly favourable. The average agreement was $84 \%$ (agree or strongly agree) that the material was understandable, the content was well organized, and the modules met their stated learning objectives. Some 77\% agreed that the modules' exercises and links were helpful. Although the majority of the respondents rated the program's overall usability as high, two individuals reported difficulties with opening some of the links within the modules and three had difficulty navigating through certain modules. To minimize such difficulties in the future, a "how to navigate" page was designed and uploaded. Furthermore, four people reported difficulty saving their work on the web to print later. Unfortunately, this was a limitation of the open-access software and could not be circumvented. However, the pharmacists were reminded to print the screen with their answers onto a word document if they desired to save their work. Finally, there were two instances where the therapeutic content needed to be upgraded to be in line with the latest treatment guidelines. A clinician was hired to replace the existing examples with new material using therapeutic content that was less likely to change.

\section{Discussion}

The most potent interface between pharmacy education and pharmacy practice occurs in experiential settings where students are provided with real-world opportunities to apply 
Table 3 Reasons for participating in the pilot study

Theme I: to enhance preceptor skills $(n=23)$

- To improve preceptorship skills

- To play a positive role in students' education

- To provide a supportive learning environment where students can practice and apply concepts and skills learned in the classroom to practical scenarios

- To gain confidence as a preceptor

- To align students' learning with the university's experiential guidelines

- To better understand documentations completed by students for various experiential activities

- To improve feedback skills regarding PC processes such as patient interviewing, care plans, and thinking through alternative treatments

Theme 2: development of professional and personal skills $(n=5)$

- To improve personal PC skills

- To learn about strategies and tools that can support effective delivery of care (identifying and formulating DRPs and writing care plans and professional notes)

Theme 3: required or preconditions $(n=3)$

- Recommended by the university or employer prior to taking students Abbreviations: $n$, number of pharmacist respondents; PC, patient care; DRPs, drug-related problems.

and practice competencies learned in the classroom. ${ }^{6,8}$ With the pharmacy profession moving towards PC, this shift provides rationale for the increased emphasis on experiential education and preceptor preparation. Experiential learning should be structured to ensure that students develop therapeutic relationships with patients, interview patients to obtain meaningful histories, assess their drug-related needs, identify existing or potential DRPs, design and implement care plans to resolve or prevent the problems, and assume responsibility through follow-up to ensure that the planned outcomes are met. ${ }^{3,4}$ While many schools are exploring strategies to promote the practice of these competencies in Introductory Pharmacy Practice Experiences (IPPEs) and APPEs, the challenge remains to recruit skilled preceptors who can provide practice centered learning opportunities that are aligned with curricular expectations and guidelines. ${ }^{20-26}$ The findings of this pilot study demonstrated that preceptor education offered through a self-study online module series improved confidence for a test group of pharmacists as preceptors for PC-based APPEs. The majority of pharmacists intend to apply their new knowledge and skills to their next student cohort. Moreover, the online module series offered the benefits of convenience, ready accessibility, and selfdirectedness by giving control over the content, learning pace, and access to materials directly to the learners. ${ }^{28-32}$

When recruiting pharmacies as potential APPE sites, earlier studies have established that enthusiasm about PC and student learning is not sufficient to ensure that PC objectives are fully met. Schools must offer development programs to
Table 4 Key learning from the online module series

Theme I: professional development

I. Better understanding of the PC practice model:

- Differentiate between three levels of PC in practice including comprehensive, disease management, and basic (goals and process)

- How the triage process can be used to move patients between the three levels of care

2. Better understanding of the PC process and how to apply it in practice:

- PC and informed shared decision making

- Importance of providing monitoring and follow-up

3. Better understanding of and access to various PC tools:

- How various PC tools can be applied in practice to support PC

- Awareness of different types of documentation tools and professional writing approaches and their place in practice

- Importance of clear documentation

4. Better understanding of DRPs:

- Clarification on the different categories of DRPs

- Benefits of using a systematic approach for identifying DRPs

- Why a clearly formulated DRP statement can facilitate appropriate recommendation(s)

5. Skills development:

- To improve communication with patients

- Improved skills to identify DRPs

- How to interview patients for comprehensive PC

- How to formulate DRP statements

- How to use a systematic approach to identify DRPs

- How to document assessment and follow-up

- How to formulate a care plan

Theme 2: enhance preceptorship competencies

I. Improved knowledge regarding:

- Experiential requirements and expectations

- How students are taught PC in the classroom

- How students are prepared for experiential learning

- How to recruit appropriate patients for PC

- What to look for when grading PC processes completed by students

- Value of giving immediate feedback

- Elements of providing effective constructive feedback

2. Improved ability and skills to support students:

- Develop an extensive experiential activity schedule

- Provide proper orientation to experiential site

- Promote self-directed learning

- Support learning without over-supporting students

- Motivate students to engage in PC

- Integrate learning with practice

- Work with struggling students

- Cultivate critical thinking and a logical/systematic approach to decision making

- Provide constructive feedback on various PC processes such as communication skills, therapeutic relationships, interviewing skills, identifying and stating DRPs, documenting care plan and writing professional notes

- Evaluate critical thinking process for identifying DRPs and developing care plans

- Provide final evaluation

3. Improved attitude

- Allow students adequate time to provide and complete care with each patient

- Incorporate different levels of PC to enrich students' learning

- Recognize the importance of feedback, the evaluation process, and providing reinforcement of success

Abbreviations: PC, patient care; DRPs, drug-related problems. 
Table 5 Changes participants intend to make as a result of the online modules

Theme I: improve teaching methods

- Provide a better learning environment for students

- Develop a calendar of activities ahead of time

- Provide many different PC opportunities

- Evaluate work in line with experiential guidelines

- Provide more effective feedback and evaluation by spending more time

- Take a more active role in students' experiences, not just during evaluations (directly observe students, provide them with challenging learning tasks, use "what if" situations, use tips to motivate students, allow autonomy but remain available, avoid giving them the right answer right away

- Stress the importance of clear, concise, and accurate documentation and communication

- Help students understand the benefits of PC and better utilize pharmacy care plans

- Engage struggling students early on

- Encourage students to use PC tools to help bridge the gap between paper cases and real patients when assessing their patients

Theme 2: professional practice

- Incorporate some of the skills, particularly written documentation in clinical practice

- Use PC tools more often when evaluating patients

Theme 3: no change

- Will continue with the status quo

- The module reinforced my current skills and knowledge on precepting pharmacy students

- No specific changes, but I will reflect on what I have learned from the online module

Abbreviation: PC, patient care.

help preceptors get started. ${ }^{6,8,12,18,20,21,27}$ The pharmacists in this study confirmed the need for preceptor development by noting that their primary reasons for participating in the training were "to improve their skills as a preceptor" and "to improve student experience."

Experiential learning environments are complex because preceptors must deal with two sets of needs: the health care needs of patients and the learning needs of students. ${ }^{6,9,10}$ Because most pharmacists are simultaneously evolving their own knowledge, skills, and PC practices, it can be difficult to engage students in PC activities that are not fully implemented in the routine environment of the practice site. Preceptors have a much easier task fulfilling both sets of needs in situations where the site practices match the students' learning needs. Real challenges arise when there is a mismatch; for example, when schools expect preceptors to provide students with PC learning opportunities such as continuity of care through to follow-up, but their in-store practices are centered on simply dispensing and refilling prescriptions. ${ }^{20,25}$ The majority of this study's participants reported that the module series helped them to better understand the PC philosophy; to consider a practice model that could be applied to patient scenarios commonly encountered in practice; to triage and transition patients to different levels of PC (from basic care, to disease management, and comprehensive consultation); and to provide care aligned with their patients' drug-related needs and their sites' infrastructures and services (Table 4). Therefore, they realized that $\mathrm{PC}$ was not just about doing comprehensive consultations, but also about a philosophy of practice that applies to all PC interactions where the continuity of care mandate encourages patients to transition from one level to the next. One preceptor stated, "[I am now aware of the] different levels of PC - comprehensive, disease management, and basic - not just the levels of PC our earlier generation of pharmacists were taught a few years ago," and "[with this knowledge I will] provide students with as many different PC opportunities and experiences as possible."

Furthermore, a number of pharmacists noted that the interactive assignments, examples, tips, and answer keys helped refresh and expand their own PC knowledge and skills. Since the foundational PC competencies were new to the curriculum, several pharmacists had received no formal training in these areas. The most valued areas were learning how to develop informed shared decision making with patients, skills for effectively identifying DRPs, learning about different professional writing styles, developing care plans for patients, developing a deeper understanding of the importance of documenting care, developing monitoring parameters, and providing follow-up care. The most striking feedback report from pharmacists was their increased understanding of the value of using a systematic thought process to identify DRPs. This was highlighted by three specific comments: "[I intend to] repeat the thought process in every (patient) case discussion with the student," "I will use different techniques to help students develop a logical and systematic approach to decision making," and "I intend to encourage my students to embrace a thought process to work through patients. To encourage utilization of this tool to help them assess patients, [and to] bridge the gap from paper cases to real patients."

Almost half of the preceptors mentioned how the module sequence contributed to their own professional development and mentioned how the modules enhanced their own PC competencies by providing them with "useful tools to apply to (their) practice." Since role modeling is a critical component of pharmacists' professional development, comfort with PC skills and tools to facilitate care delivery enables preceptors to demonstrate best practices and to discuss their decisions to make sure that students understand the rationale. On many occasions, students cannot see what experts 
intuitively observe; therefore, the strategies and tools in the module series allows preceptors to talk about their decision sequences and to point out their significance to students. ${ }^{33}$ While modeling higher-level thinking may seem unnatural at first, one pharmacist noted "with practice... it will become second nature."

Curricular changes in schools have added additional challenges for preceptors. Most preceptors have been trained in traditional teacher-centered models; therefore, it is not immediately intuitive to them how to best facilitate student engagement in PC. ${ }^{34}$ Student-centered learning requires that preceptors have the requisite skills to encourage students to use their own knowledge and to make informed decisions while providing PC. The module series provided preceptors with strategies and tools to facilitate such learning and succeeded in persuading them that APPE students need to take greater responsibility for their own PC learning. They reported, "[I learned]... how to be supportive of students without coddling them," "[how to] evaluate the situation to (assess) when best to teach and when to have the student look up (the) answer," "to allow students autonomy, but remain available when help is needed, to spend more time on (the) feedback process and evaluation," "to use 'what if' situations to promote critical thinking...," and to "facilitate students' learning (by)... avoiding giving them the right answer right away but providing feedback along the way." In addition, the pharmacists valued the integration between the PC content and the experiential education approaches. They reported increased post-training confidence in setting expectations, evaluating students' ability to apply PC competencies in practice, and fostering critical thinking and problem solving skills. One preceptor stated, "I learned different ways of thinking of the student related problems and issues." Another mentioned the value "... of having [an activity] calendar established ahead of time." Good teaching requires planning; thus, in recognizing the value of their own preparation prior to the students' arrival at the site, preceptors can make student education more effective by pre-structuring a variety of learning experiences.

Preceptors are responsible for the on-site actions of their students; therefore, they must observe the students in action, review patient cases and care plans, ensure the delivery of appropriate care, and provide direction and constructive feedback when needed. This requires a fine balance of interdependence that allows students to practice independently while monitoring them for safety and appropriateness - activities characteristic of appropriate scaffolding while engaged in the "zone of proximal development." 35,36
The pharmacists believed the module series equipped them to better gauge the strengths and weaknesses of their students; hence, they felt more confident in their ability to assess and to give feedback and to evaluate the next cohort of students. A student comment commonly seen in experiential evaluations is "my preceptor did not spend enough time with me at my pharmacy practice site." ${ }^{21}$ At first, such comments may suggest a lack of interaction because of the preceptor's workload, but in reality, it may result from a lack of direction or absence of specific expectations from the preceptor as to what discussions would most benefit the student. ${ }^{37}$ Successful training promotes changes in both understanding and practice. The pilot study participants offered the following ideas: “ $\ldots$ be more involved with the students throughout their placement, not just during their evaluation... directly observe...," "engage struggling students very early on," “... take a more active role in our students' experience by ensuring they formulate appropriate and beneficial care plans for our patients," "as my understanding (of APPE expectations) is enhanced, I will be able to evaluate their work more in line with (APPE) guidelines," and "Give more timely feedback... around thought process of care plans and alternative treatment options."

\section{Limitations}

As always, this study has limitations. The primary limitation is the comparatively small participant number and their geographic locations, which limits the generalizability of the findings. The pharmacists registered in this training all resided within the Canadian province of British Columbia. Additionally, a majority were affiliated with institutional settings, and only approximately $12 \%$ of the participants represented community practices since most attended the live version of the program. Therefore, the views and experiences of preceptors outside the province and in settings may differ. The demographic information collected in this pilot study was also limited and does not allow for the interpretation of specific preceptor characteristics such as number of years since graduation, total numbers of students precepted since graduation, previous preceptor training, and so on. However, given the commonality of PC practice and curriculum structures across other experiential programs, considerable perspective overlap is bound to occur. A second limitation is self-assessment as a measure of the training's impact on the pharmacists' confidence levels. Self-assessments are subject to internal validity threats such as flawed judgement, over-confidence, "faking-good," or even Hawthorne effects. While the pre-post design helped improve internal validity, 
a post-pre study should also be considered. To augment the findings in this study, future studies should consider wider target populations, greater varieties of settings, and should employ experimental designs that measure actual content gains.

\section{Conclusion}

This paper describes the development and evaluation of a series of online modules aimed at educating and preparing pharmacists to function as preceptors for a PC-based advanced practice experience. As the profession of pharmacy shifts from a product to a PC focused practice, experiential learning is likely to be the cornerstone for cultivating relevant competencies in practice. To achieve this goal, schools of pharmacy will need to invest in training preceptors and students. This study's results suggest that a series of selfpaced online modules with appropriate content can improve pharmacists' confidence to nurture students' experiential learning for PC practice and to enhance their own PC knowledge and skills.

\section{Acknowledgments and disclosure}

The authors report no conflicts of interest in this work. The authors meet the criteria for authorship as recommended by the International Committee of Medical Journal Editors. John B Collins received consultancy fees for analysis and interpretation of the study data. The authors received no compensation related to the development of the manuscript.

\section{References}

1. Joint Commission of Pharmacy Practitioners. Joint Commission of Pharmacy Practitioners. Future Vision of Pharmacy Practice. Alexandria, VA; 2004.

2. pharmacist.com [homepage on the Internet]. Washington: American Pharmacists Association; 2012. Available from: http://www.pharmacist. com. Accessed May 8, 2012.

3. Accreditation Standards and Guidelines. Chicago: Accreditation Council for Pharmacy Education (ACPE); 2011. Available from: http:// www.acpeaccredit.org/standards/default.asp. Accessed October 8, 2011.

4. Accreditation of Pharmacy Programs in Canada. Canadian Council for Accreditation of Pharmacy Programs (CCAPP); 2011. http:// www.ccapp-accredit.ca/obtaining_accreditation. Accessed October 8, 2011.

5. Haase KK, Smythe MA, Orlando PL, Resman-Targoff BH, Smith SL; American College of Clinical Pharmacy. Quality experiential education. Pharmacotherapy. 2008;28:1547.

6. Dugan BD. Enhancing community pharmacy through advanced pharmacy practice experiences. Am J Pharm Educ. 2006;70:21

7. American Association of Colleges of Pharmacy. Academic-Practice Partnership Initiative Report. Pilot project to profile Exemplary Advance Practice Experience Site. 2006;1-99.

8. American Pharmacists Association and National Association of Chain Drug Stores. The Community Pharmacist Preceptor Education Program. Continuing Education Program. 2010;1-40.
9. Brackett PD, Byrd DC, Duke LJ, et al. Barriers to expanding advanced pharmacy practice experience site availability in an experiential education consortium. Am J Pharm Educ. 2009;73(5):82.

10. Lee KW, Machado MR, Wenzel MM, Gagnon JM, Calomo JM. An advanced professional pharmacy experience in a community setting using an experiential manual. Am J Pharm Educ. 2006; 70(2):42.

11. Fincham JE. The need to invest in community pharmacy practice. Am J Pharm Educ. 2007;71(2):26.

12. Kassam R, Volume-Smith CI. Focus Group Methodology to Develop a Community Pharmaceutical Care Clerkship Program. Am J Pharm Educ. 2003;67(3):88.

13. McDonough RP, Rovers JP, Currie JD, et al. Obstacles to the implementation of pharmaceutical care in the community setting. JAm Pharm Assoc. 1998;38:87-95.

14. Bosso JA. Clinical pharmacy and pharmaceutical care. Pharmacotherapy. 2004;24:1499-1500.

15. Franklin BD, van Mil JW. Defining clinical pharmacy and pharmaceutical care. Pharm World Sci. 2005;27(3):137

16. Kassam R, MacLeod E, Collins J, et al. Meeting the clinical education needs of community-based preceptors: an environmental scan to identify format and content for a new web-based resource. The Internet Journal of Allied Health Sciences and Practice. 2011;9(2):1-9. Available from: http://ijahsp.nova.edu. Accessed March 5, 2012.

17. Marriott J, Duncan G, McNamara K. Barriers to Pharmacist Participation in Continuing Education in Australia. Pharm Educ. 2007;7(1): $7-11$

18. Kassam R, Kwong M. An enhanced community advanced pharmacy practice experience model to improve patient care. Am J Pharm Educ. 2009;73(2):25.

19. Cook DA, Levinson AJ, Garside S, Dupras DM, Erwin PJ, Montori VM. Instructional design variations in internet-based learning for health professions education: a systematic review and meta-analysis. Acad Med. 2010;85:909-922.

20. Kassam R. Evaluation of pharmaceutical care opportunities within an advanced pharmacy practice experience. Am J Pharm Educ. 2006;70(3):49.

21. Kassam R. Students' and preceptors' experiences and perceptions of a newly developed community pharmacy pharmaceutical care clerkship. Pharm Educ. 2006;6(3):179-188.

22. Cerulli J, Briceland LL. A streamlined training program for community pharmacy advanced practice preceptors to enable optimal experiential learning opportunities. Am J Pharm Educ. 2004;68(1):Article 9.

23. MacKinnon GE 3rd. Documentation: a value proposition for pharmacy education and the pharmacy profession. Am J Pharm Educ. 2007;71(4):73.

24. Nemire RE, Meyer SM. Educating students for practice: educational outcomes and community experience. Am J Pharm Educ. 2006; $70(1): 20$.

25. Zarembski DG, Boyer JG, Vlasses PH. A survey of advanced community pharmacy practice experiences in the final year of the PharmD curriculum at the US colleges and schools of pharmacy. Am J Pharm Educ. 2005;69(1):2.

26. Boyle CJ, Morgan JA, Layson-Wolf C, Rodriguez de Bittner M. Developing and implementing an Academy of Preceptors. Am J Pharm Educ. 2009;73:34.

27. McDuffie CH, Duke LJ, Stevenson TL, et al. Consortium-based approach to an online preceptor development program. Am J Pharm Educ. 2011;75(7):135.

28. Cook DA, Thompson WG, Thomas KG, Thomas MR, Pankratz VS. Impact of self-assessment questions and learning styles in Web-based learning: a randomized, controlled, crossover trial. Acad Med. 2006;81:231-238

29. Phillips JM. Preparing preceptors through online education. J Nurses Staff Dev. 2006;22(3):150-156.

30. Ruiz JG, Mintzer MJ, Leipzig RM. The impact of E-learning in medical education. Acad Med. 2006;81(3):207-212. 
31. Marriott J, Taylor S, Simpson M, et al. Australian national strategy for pharmacy preceptor education and support. Aust J Rural Health. 2005;13(2):83-90.

32. Elliott RA, McDowell J, Marriott JL, Calandra A, Duncan G. A pharmacy preregistration course using online teaching and learning methods. Am J Pharm Educ. 2009;73(5):77.

33. Benner P. From novice to expert. Am J Nurs. 1982;82(3):402-407.

34. Turner CJ, Ellis S, Giles J, et al. A strategy to develop advanced pharmacy practice experiences. Am J Pharm Educ. 2007;71(3):46.
35. Allal L, Ducrey GP. Assessment of-or in-the zone of proximal development. Learning and Instruction. 2000;10(2):132-152.

36. Vygotsky LS. Mind in Society: Development of Higher Psychological Processes. Harvard University Press; 1978:86.

37. Karimi R, Cawley P, Arendt CS. Learning bridge tool to improve student learning, preceptor training, and faculty teamwork. Am J Pharm Educ. 2011;75(3):46.

\section{Publish your work in this journal}

Advances in Medical Education and Practice is an international, peerreviewed, open access journal that aims to present and publish research on Medical Education covering medical, dental, nursing and allied healthcare professional education. The journal covers undergraduate education, postgraduate training and continuing medical education including emerging trends and innovative models linking education, research, and healthcare services. The manuscript management system is completely online and includes a very quick and fair peer-review system. Visit http://www.dovepress.com/testimonials.php to read real quotes from published authors.

Submit your manuscript here: http://www.dovepress.com/advances-in-medical-education-and-practice-journal 